\title{
Biokinetics of soluble plutonium after wound injury treated with Ca-DTPA
}

\author{
Maia Avtandilashvili ${ }^{1, *}$ and Sergei $Y$. Tolmachev ${ }^{1}$ \\ ${ }^{1}$ U.S. Transuranium and Uranium Registries, College of Pharmacy, Washington State University, \\ 1845 Terminal Drive, Suite 201, Richland 99354, WA, USA
}

\section{Introduction}

The mission of the United States Transuranium and Uranium Registries (USTUR) is to study the uptake, translocation, retention and excretion (biokinetics), and tissue dosimetry of uranium, plutonium, americium, and other actinides in occupationally exposed volunteer Registrants (tissue donors). These individuals were mainly exposed to various types of plutonium material with inhalation and wound as primary routes of intake. The USTUR holds records on exposure history and bioassay measurements, as well as post-mortem tissue radiochemical analysis results for 19 individuals who had documented intakes of ${ }^{239} \mathrm{Pu}$ due to contaminated wounds. For 8 individuals, internal deposition resulted from a single wound injury, and three of them were treated with decorporation therapy. In this study, USTUR Case 0303 was used to study biokinetics of soluble Pu after wound intake.

\subsection{Case description}

The USTUR whole-body donor (Case 0303) was employed at nuclear defence facility for 30 years. While working in a glove-box, he accidentally punctured his finger on a sharp object contaminated with plutonium nitrate. The contaminated tissue was surgically excised and found to contain approximately $2.33 \mathrm{kBq}$ of ${ }^{239} \mathrm{Pu}$. A wound count performed four weeks later indicated that $59 \mathrm{~Bq}$ of ${ }^{239} \mathrm{Pu}$ still remained in the finger. Worksite personnel estimated systemic deposition of ${ }^{239} \mathrm{Pu}$ due to this accident as $85 \mathrm{~Bq}$. This individual was medically treated with intravenous injections of Ca-DTPA. A total of $16 \mathrm{~g} \mathrm{Ca-DTPA}$ was administered in 18 treatments during two months following the accident. Eighty-seven urine samples were collected and analysed over 14 years following the accident. This individual died 40 years post-intake at age 87 .

\section{Materials and Methods}

Thirty-two soft tissue and 8 bone samples collected at autopsy were radiochemically analysed for ${ }^{238} \mathrm{Pu},{ }^{239} \mathrm{Pu}$ and ${ }^{241} \mathrm{Am}$. A complete description of the radiochemical analysis protocol has been described elsewhere [1]. To estimate the plutonium intake, late urine measurements (past 100 days after the last Ca-DTPA injection), which were unaffected by chelation, and post-mortem radiochemical analysis results were evaluated using the IMBA Professional Plus ${ }^{\circledR}$ software [2].

${ }^{*}$ Corresponding author: m.avtandilashvili@,wsu.edu 


\section{Results and Discussion}

Post-mortem radiochemical analysis of autopsy tissues indicated that forty years postaccident $12.2 \pm 0.3 \mathrm{~Bq}$ of ${ }^{239} \mathrm{Pu}$ was retained in the liver and $17.5 \pm 0.7 \mathrm{~Bq}$ in the skeleton. Activity measured in the skin and muscle tissue sample from the wound site was $0.26 \pm 0.01$ $\mathrm{Bq}$ while activity in the finger bone adjacent to the wound was measured as $1.09 \pm 0.03 \mathrm{~Bq}$. Thus, a total of $1.35 \mathrm{~Bq}$ of ${ }^{239} \mathrm{Pu}$ was retained in the wound.

Activity in the lungs including thoracic lymph nodes was estimated to be $0.14 \pm 0.01 \mathrm{~Bq}$, two orders of magnitude lower than activity in the liver. This observation confirmed the assumption of the soluble plutonium intake via wound injury to be the major source of internal contamination for this individual.

Application of the NCRP 156 wound model [3] with default parameters for soluble strong material resulted in a credible fit to the data $(\mathrm{p}>0.05)$ (Fig. 1). The residual intake was estimated to be $47.6 \mathrm{~Bq}$ and estimated committed effective dose was $24.1 \mathrm{mSv}$. By accounting for $\sim 77.8 \mathrm{~Bq}$ of ${ }^{239} \mathrm{Pu}$ excreted during Ca-DTPA treatment, the total intake was estimated to be $125 \mathrm{~Bq}$. Without Ca-DTPA treatment, this individual would have received committed effective dose of $63.3 \mathrm{mSv}$. Chelation therapy reduced radiation dose by a factor of 2.6.

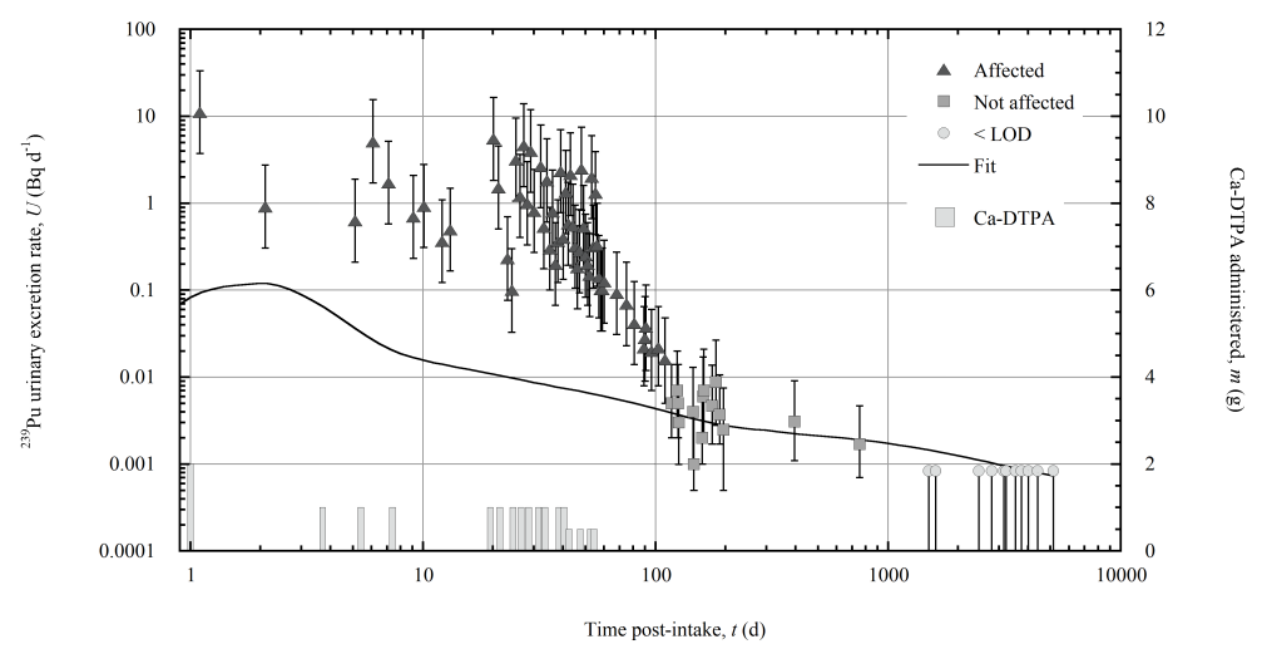

Fig. 1. ${ }^{239} \mathrm{Pu}$ daily urinary excretion and Ca-DTPA treatment data.

\section{References}

1. S. Y. Tolmachev, M. E. Ketterer, D. Hare, P. Doble, A. C. James. Proc Radiochimica Acta 1, 173 (2011).

2. A. Birchall, M. Puncher, J. W. Marsh, K. Davis, M. R. Bailey, N. S. Jarvis, A. D. Peach, M. D. Dorrian, A. C. James. Radiat Prot Dosim 125, 194 (2007).

3. National Council on Radiation Protection and Measurements. NCRP Report 156, (2007). 